\title{
AN APPROACH TO IAEA MATERIAL-BAI ANCE VERIFICATION WITH INTERMITTENT INSPECTION AT THE PORTSMOUTH GAS CENTRIFUGE ENRICHMENT PLANT
}

David M. Gordon and Jonathan B. Sanborn

TECHNICAL SUPPORT ORGANIZATION DEPARTMENT OF NUCLEAR ENERGY

May 18, 1984

Prepared for the

OFFICE OF SAFEGUARDS AND SECURITY

U.S. DEPARTMENT OF ENERGY

WASHINGTON, D.C. 20545

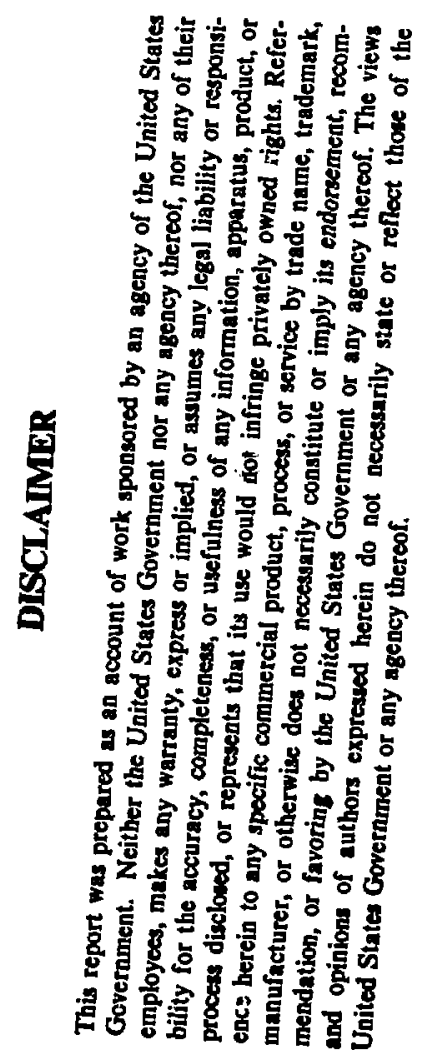


ABSTRACT. $\mathbf{v i}$

I. Introduction $\ldots \ldots \ldots \ldots \ldots \ldots \ldots \ldots \ldots \ldots \ldots \ldots \ldots \ldots \ldots \ldots \ldots \ldots \ldots$

A. Review of Relevant Results from the Hexapartite Safeguards Project

B. Review of the IAEA Material-Balance-Verification Approach

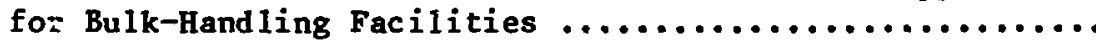

C. Application of the Attributes/Variables Approach to GCEP ... 5

II. $\mathrm{UF}_{6} \mathrm{Cy}$ linder-Handling Operations $\ldots \ldots \ldots \ldots \ldots \ldots \ldots \ldots \ldots \ldots$

III. An Approach to Material-Balance Verification with

Intermittent Inspections $\ldots \ldots \ldots \ldots \ldots \ldots \ldots \ldots \ldots \ldots \ldots \ldots \ldots \ldots \ldots \ldots$

A. Description of the Approach $\ldots \ldots \ldots \ldots \ldots \ldots \ldots \ldots \ldots \ldots \ldots \ldots \ldots 11$

B. Probability of Detection $\ldots \ldots \ldots \ldots \ldots \ldots \ldots \ldots \ldots \ldots \ldots \ldots \ldots$

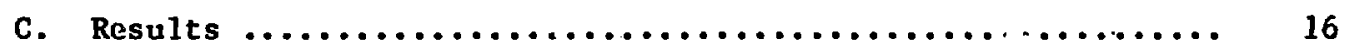

1. Product Cylinders $\ldots \ldots \ldots \ldots \ldots \ldots \ldots \ldots \ldots \ldots \ldots \ldots \ldots \ldots$

2. Feed Cylinders $\ldots \ldots \ldots \ldots \ldots \ldots \ldots \ldots \ldots \ldots \ldots \ldots \ldots \ldots \ldots . \ldots \ldots$

3. Tails Cylinders $\ldots \ldots \ldots \ldots \ldots \ldots \ldots \ldots \ldots \ldots \ldots \ldots \ldots \ldots \ldots . \ldots$

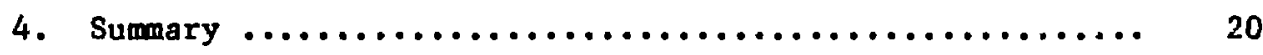

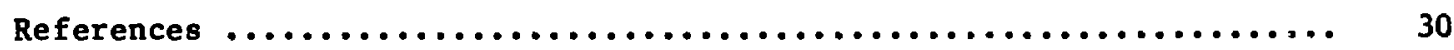




$$
\text { List of Tables }
$$

Table No.

Title

$\underline{\text { Page }}$

$\mathbf{I}$

Feed, Product and Tails Flow Rates for the

Portsmouth Gas Centrifuge Enrichment Plant

(1100 tonne swU/year) .......................

Detection Probabilities for the Intermittent Ins pection Approach ......................

Parameters for Calculation of Detection Probability

$P_{D}$ (Separative Capacity of 1100 tonne SwU/year)..... 


\section{List of Figures}

Figure No.

Title

Page

1

2

3

4

5

6

7

8

9
Detection Probability $\left(P_{D}\right)$ as a Function of Residence Time $\left(T_{1}\right)$ for $N=12$ Inspections

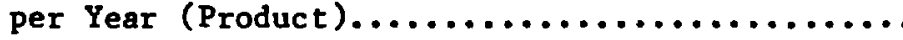

Detection Probability $\left(P_{D}\right)$ as a Function of Residence $T$ ime $\left(T_{1}\right)$ for $N=15$ Inspections

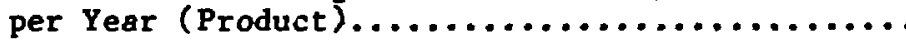

Detection Probability $\left(P_{D}\right)$ as a Function of Residence $T$ ime $\left(T_{1}\right)$ for $N=20$ Inspections per Year (Product)......................

Detection Probability $\left(P_{D}\right)$ as a Function of Residence Time $\left(T_{1}\right)$ for $N=12$ Inspections per Year (Feed)

Detection Probability $\left(P_{D}\right)$ as a Function of Residence Time $\left(T_{1}\right)$ for $N=15$ Insnections per Year (Feed)

Detection Probability $\left(P_{D}\right)$ as a Function of Residence Time $\left(T_{1}\right)$ for $N=20$ Inspections per Year (Feed)

Detection Probability $\left(P_{D}\right)$ as a Function of Residence Time $\left(T_{1}\right)$ for $N=12$ Inspections

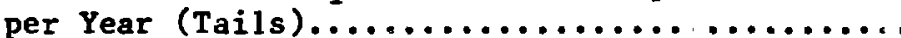

Detection Probability $\left(P_{D}\right)$ as a Function of Residence Time $\left(T_{1}\right)$ for $N=15$ Inspections per Year $(\mathrm{Tails}) \ldots \ldots \ldots \ldots \ldots \ldots \ldots \ldots \ldots \ldots$

Detection Probability $\left(P_{D}\right)$ as a Function of Residence $T$ ime $\left(T_{1}\right)$ for $N=20$ Inspections

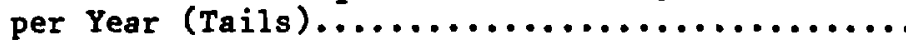




\section{ABSTRACT}

This paper describes a potential approach by which the International Atomic Energy Agency (IAEA) might verify the nuclear-material balance at the Portsmouth Gas Centrifuge Enrichment Plant (GCEP) for the circumstance in which the IAEA inspections occur on an intermittent basis. The verification approach is a variation of the standard IAEA attributes/variables measurement-verification method. This alternative approach is useful and applicable at he Portsmouth GCEP, which will ship all its product and tails UF 6 to United States facilities not eligible for IAEA safeguards. The paper reviews some of the relevant results of the Hexapartite Safeguards Project (HSP), describes the standard IAEA materialbalance-verification approach for bulk-handling facilities, and provides the procedures to be followed in handling and processing $\mathrm{UF}_{6}$ cylinders at the Portsmouth GCEP. The paper then discusses the assumptions made in the approach, and derives a formula for the probability with which the IAEA could detect the diversion of a significant quantity of uranium (75 $\mathrm{kg}$ of $\mathrm{U}-235$ in depleted, nor$\mathrm{ma}$, and low-enriched uranium) if this method were applied. The paper also provides numerical examples of IAEA detection probability should the operator divert uranium from the feed, product, or tails stzeams for the Portsmouth GCEP with a capacity of 1100 tonnes of separative work per year. 


\section{INTRODUCTION}

A. Review of Relevant Results from the Hexapartite Safeguards Project The Hexapartite Safeguards Project (HSP) agreed on some fundanental conclusions regarding international safeguards at gas-centrifuge enrichment plants. 1 First, it was agreed that implementation of the objective of safeguards entails a set of safeguards measures whose application by the Inspectorate(s) permits the detection, in a timely manner and with high confidence, of the diversion of a significant quantity of uranium, including the production of a significant quantity of uranium at an enrichment level higher than declared. In considering diversion strategies, it was agreed that special emphasis must be placed on meeting the relevant goals for strategies involving material of high strategic value. Second, it was agreed that the detection of highly enriched uranium (HEU) production is adequately addressed by cascade-hall access (including visual observations and non-destructive assay measurements). Third, it was agreed that the basic measures consisting of the verification of operator material accountancy, with the aid of independent measurement and conventional containment/surveillance $(\mathrm{C} / \mathrm{s}$ ) at strategic points outside the cascade halls, will provide a timely detection capability for significant diversions of low enriched, natural or depleted uranium. In this context, the HSP agreed that the detection goals relevant to material-balence verification activities are those relevant to low-enriched uranium (LEU) diversion; namely, $75 \mathrm{~kg} \mathrm{U-235} \mathrm{in}$ about one year.

During the course of the HSP, the limited-frequency, unannounced access (LFUA) safeguards approach was proposed and adopted by the HSP participants. All the technology holders in HSP desired that the International Atomic Energy Agency (IAEA) inspections be intermittent. However, the HSP participants 
agreed that provisions should be made to give the Inspectorate(s) the opportunity to verify the feed, product, and tails before they are fed to or shipped from the plant. It was also agreed that the mode of the material-balanceverification inspections would be intermittent; based on the discussions and agreements of the HSP, it appears that an approximate average frequency of 1215 times per year could be anticipated for such inspections at facilities up to about 1000 tonne SWU/yr. It is anticipated that an average duration for an intermittent routine inspection visit would be 3 working days provided that the conditions at the plant allow the inspection activities to be carried out without delay or interruption. Usually it is IAEA practice to send at least 2 inspectors to perform the inspection activities. It was further agreed that a deterrent value, although largely unguantifiable, would be derived from the unannounced random charpcter of inspection activities.

B. Review of the IAEA Materia1-Balance-Verification Approach for BulkHandling Facilities

For bulk-handing facilities such as Portsmouth Gas Centrifuge Enrichment Plant (GCEP), the operator will report his material-balance measurements and his material-unaccounted-for (MUF) for each material-balance area (MBA) in accordance with the safeguards agreement for that facility; the IAEA verifies the material balance declared by the operator.

This structure of reporting and verification presents two potential strategies to an operator who might wish to divert material from the material balance. He could report an unfalsified material balance (accurately reporting his own measurements) and divert an amount such that the reported MUF is within the range of the uncertainty in his material balance, implying or stating that this MUF resulted from measurement uncertainties. This strtegy is sometimes 
called "diversion into MUF". Alternatively, he might falsify his reported measurements by understating reported inputs or overstating reported outputs or inventory so as to reduce his reported MUF. The magnitude of these falsifications could 1 ie anywhere in the range fros very large to very small. For example, an operator might choose to falsify the contents of one or a few containers by large amounts and hope that the IAEA would not perform any measurements on those containers. At the cther extreme, the operator might choose to falsify the contents of a large number of containers by small amounts, and hope that the IAEA would not be able to measure accurately and precisely their true contents. It is convenient to define two levels of falsification: a "defect" and a "bias". We will use the term "defected item" to denote an item whose reported U-235 content differs from its true value by an amount which is significantly greater than the combined uncertainties of the operator's measurement and the IAEA's best measurement for that item. This means that an anomaly will be very clearly indicated if the IAEA decides to measure accuracely a defected item. A "bias" is a falsification by an amount smaller than a defect; thus, a bias is not detectable by the IAEA frow a single measurement on an item.

The IAEA has adopted a material-balance-verification strategy which is designed to detect effectively and efficiently both "diversion into MUF" and falsifications of material-balance quantities by large and small amounts (i.e., falsification by "defects" and "biases"). This strategy is specified in the IAEA Safeguards Technical Manua.$^{2}$ It makes use of "attributes" and "variables" measurements performed by the IAEA on a randomly selected sample of the items comprising the uranium flows and inventories at the facility. An "attributes" measurement is one which may be performed quickly but which is relatively less precise and accurate; such a measurement is performed on a relatively large 
fraction of the jitems in order to detect large falsifications. An example of an attributes measurément is the non-destructive measurement of the U-235 concentration for $\mathrm{UF}_{6}$ in a cylinder by gamma-ray counting. A "variables" measurement is one which has high precision and accuracy but which is often time-c nsuming and expensive to perform; it uses the IAEA's most accurate measurement method for an item. Variables measurements are performed to detect small falsificat:-ons (i.e., falsifications small enough to escape detection by the attributes measurement) and to detect biases. An example of a variables measurement is the measurement of the U-235 concentration of $\mathrm{UF}_{6}$ by mass spectrometry. This twolevel strategy of attributes and variables measurements is efficient because (1) the attributes test can be performed quickly, and (2) if the attributes test is performed, a diverter wishing to avoid detection would be forced to make a larger number of falsifications of a smaller size; this enables the IAEA to reduce its variables-test sample size. Thus, the two-level system would reduce the effort that must be expended in destructive analyses while maintaining the ability to detect diversion.

In order for the verification results of the at:ributes/variables method to be valid, the IAEA should be able to measure, on a random basis, any item whose content has been reported by the operator. In addition, the random sample of items selected for measurement verification by the IAEA must be taken in such a manner as to deny the operator the ability simply to falsify the contents of unverified items. There are two methods for accomplishing this.

In the first method, the IAEA obtains a sample for all unsealed items in the flow and inventory strata and then selects, at random and without know1edge of the operator, the necessary number of samples for measurement verification. In the second method, the operator declares (and is committed to) the 
measurement values and U-235 contents of items before itens are selected for measurement verification by the IAEA. The IAEA can then select, at randon and with the knowledge of the operator, those items to be verified. This latter method is used by the IAEA for physical-inventory verification.

C. Application of the Attributes/Variables Approach at GCEP The maior flows of uranium to and from the plant will be in the form of feed, product, and tails UF 6 in 9.5- and 12.5-tonne cylinders; the present discussion will be limited to these three strata. The data declared by the operator will include the $U$ and $U-235$ weight for each cylinder. In order to verify these flows of $U$ and $U-235$, the IAEA could verify the following quantities for cylinders tran'serred to and from the cascades:

- net mass of $\mathrm{UF}_{6}$ transferred (determined from gross-fu11 and gross-empty cylinder weights);

- uranium weight fraction; and

- U-235 weight fraction.

In principle, the IAEA could use the attributes/variables measurement approach to verify each of the three types of measurements which, taken together, define the amount of $\mathrm{U}-235$ in a cylinder. In practice, it appears that the complete attributes/variables approach probably would be applied only to the verification of the $\mathrm{U}-235$ weight fractions and perhaps the cylinder weights. A brief summary of potential verification measures is given below; a more complete description has been given elsewhere. 3

\section{Verification of Weights}

It is anticipated that cylinders will be stored in a location accessib1e to the overhead crane. In this circumstance, the cylinders could be weighed in place using the large-capacity load-ce11-based weighing system (LCBWS), 
currently undergoing test and evaluation at the Oak Ridge Gaseous Diffusion Plant. A 1 imited number of cylinders could, on occasion, be transported to operator's accountability scales for reweighing there.

\section{Verification of Uranium Height Fraction}

A sma11 number of cylinders could be liquid sampled by the GCEP operator under observation by the IAEA inspector, with the samples presented to the IAEA. The IAEA then could take steps to verify the declared uranium weight fraction if it sa chooses. Vapor-phase sampling from cold cylinders could also be used to provide samples.

\section{Verification of U-235 Weignt Fraction}

The ful1 attributes/variables method could be applied to the verification of U-235 weight fraction. The attributes measurements of enrichment could be performed on individual $1 \mathrm{UF}_{6}$ cylinders, using the standard gamma-ray nondestructive-assay (NDA) method and measuring the cylinder-wall thickness by u1trasonic means. These attributes measurements might also be performed with a different NDA system, using measurements performed on individual product cylinders with hand-held ganma-rey NDA instruments in combination with measurements performed by means of tamper-indicating, in-line enrichment monitors installed in the feed, product, and tails piping which carries UF to and from the cascades (when these monitors are available).

The variables measurements of enrichment could be performed by mass spectrometry of $\mathrm{UF}_{6}$ samples, either at the IAEA Safeguards Analytical Laboratory (SAL) or at one of the laboratories of the Network of Anaiytical Laboratories (NWAL). The $\mathrm{UF}_{6}$ samples could be withdrawn from the gas phase in IAEA-selected feed, product, and tails cylinders by the operator under observation by the IAEA inspector. 


\section{UF 6 CYLINDER-HANDL ING OPERATIONS}

It is useful at this point to review briefly the major operations that are anticipated for feed, product, and tails $U F_{6}$ cylinders when the GCEP Feed and Withdrawal (F/W) Building is operational. In the context of this paper, it is useful to note that some of the $\mathrm{UF}_{6}$ feed will come from facilities not under IAEA inspection, and that all of the GCEP product and tails UF 6 will go the facilities not eligible for IAEA inspections. Moreover, the operator needs to ship offsite the product and tails cylinders as soon as safe operations permit. The feed, product, and tails flow rates for GCEP with a 1100 tonne SwU/yr separative capacity are given in Table $I$.

\section{Feed}

Feed $\mathrm{UF}_{6}$ will be received from several suppliers in 10-ton and 14-ton cylinders. Upon receipt each feed cylinder will be unloaded and brought into the feed area of the $\mathrm{F} / \mathrm{W}$ Building to be weighed on an accountability scale. The cylinders will then be transferred to a storage area to await acceptance sampling. This sampling will occur within 7 days of the arrival of a cylinder. The feed cylinder will then be removed from the autoclave, weighed, and moved by railcar to a storage area to cool while the sample is analyzed off-site; the results of this analysis will be available within 21 days of sampling for feed cylinders. The cooling period will be 5 days. If the cylinder is accepted, it will remain in storage awaiting its turn to be taken to the feed area. Cylinders will be fed in order ur receipt. It is anticipated that the facility will maintain a stockpile of sampled $\mathrm{UF}_{6}$ feed cylinders equivalent to 75 days of operation $a i$ the then-current operating separative capacity. A cylinder scheduled to be fed will be brought into the $F / W$ feed area from the storage area, placed in an autoclave, heated, and fed to the cascades. After the cylinder is empty, 
Table I

Feed, Product and Tails Flow Rates

for the

Portsmouth Gas Centrifuge Enrichment Plant

(1100 tonne SwU/Year)

Feed Rate $(0.71 \%$ U-235)

$\operatorname{MTU} / \mathrm{Yr}$

1764

kg $\mathrm{U}-235 / \mathrm{yr}$

12542

Number of $10-$ and $14-t$ ton cylinders $/ y^{a}$

237

Product Rate (2.85\% U-235)

$\mathbf{M T U} / \mathbf{y r}$

kg U-235/yr

8914

Number of 10 -ton cylinders/yr ${ }^{b}$

Tai1s Rate (0.257 U-235)

$\mathbf{M T U} / \mathbf{y r}$

kg U-235/yr

Number of 14-ton cylinders/yr

\footnotetext{
Mode1s $48 \mathrm{X}$ and $48 \mathrm{Y}$ in equal numbers

bodel $48 \mathrm{X}$

cMode $148 G$
} 
it will be removed from the autoclave, weighed, and taken to a storage area until anothe railcar or truck arrives with full feed cylinders; the empty cylinders will be returned to the supplier by truck or by railcar.

\section{$\underline{\text { Product }}$}

Empty product cylinders will airive four at a time at the F/W Building on four-cylinder railcars. The empty cylinders will be unloaded by crane, brought to the feed area, weighed on the accountability scale, and returned to the railcar until needed. When needed, the cylinder to be filled will then be moved by crane from the railcar to a product-withdrawal station and filled with UF $_{6}{ }^{*}$ After filling, product cylinders will be allowed to cool in place for 1 to 3 days until the contents are solid; they will then be moved to the feed area of the F/W Building for accountability weighing and sampling. The sampling procadure for product cylinders will be the same as for feed cylinders--the cylinder will he loaded by crane into an autoclave, heated for 4 to $5 \mathrm{hr}$, and liquidsampled. The product cylinders will then be removed from the autoclaye, weighed, and put on a four-cylinder railear. Before shipment, product cylinders must be allowed to cool on the railcar until their contents solidify; it is anticipated that this cooling time will be 5 days. When the laboratory results are available (generally within 6 days of sampling for product cylinders), the cylinder will be shipped offsite to facilities not eligible for IAEA safeguards; thus, the product will be withdrawn from safeguards under the terms of the US / IAEA Agreement.

\section{Tails}

Empty tails cylinders will arrive four at a time at the F/W Building on four-cylinder railcars. The empty cylinders will be unloaded by crane, brought to the feed area, weigied on the accountability scale, and returned to the 
railcar until needed. When needed, the cylinder to be filled will be moved by crane from the railcar to a tails-withdrawal station and filled with UF 6 . The filled tails cylinders will be disconnected and, if time permits, be allowed to cool until their contents have solidified. They will then be removed to the feed area of $F / W$ Building for weighing. Tails cylinders not requiring sampling will be placed on railcars after their accountability weighing to await shipment. After having been weighed, those cylinders that are to be sampled either will be kept in the feed area or will be removed to a railcar to await their turn in an autoclave. The sampling procedure for tails cylinders wil? be the same as for feed cylindersthe cylinder will be loaded by crane inco an autoclave, heated for 4 to $5 \mathrm{hr}$, and liquid-sampled. Laboratory results for tails cylinders generally are availahle within 15 days of sampling. The tails cylinders will then be removed from the autoclave, weighed, and put on a four-cylinder railcar for 5-day cooling and subseque shipping. Prior to 1987, all tails cylinders will be sampled; after that, at least 107 of the tails cylinders will be sampled for accountability purposes.

The tails cylinders will be shipped offsite to facilities not eligible for IAEA safeguards, and thus will be withdrawn from safeguards under the terms of the US/IAEA Agreement. 
III. AN APPROACH TO MATERIAL-BALANCE VERIFICATION WITH INTERMITTENT INSPECTIONS

As noted above, the operator needs to ship product and tails cylinders offsite as soon as safe operations permit. On the other hand, the IAEA needs to have the opportunity to verify the feed, product, and tails before they are fed to or shipped from the plant. A verification approach has been suggested which provides the IAEA with the opportunity to verify cylinder contents while keeping the burden on the operator, and interference with cylinder-handling procedures, to acreptable levels. ${ }^{4}$ This concept is described briefly below.

A. Description of the Approach

The concept makes use of the second method described above in Section I.B. for obtaining a random sample in a manner such that the operator cannot simply falsify the contents of unverified items; namely, the operator declares (and is committed to) the measurement values for items before items are selected for measurement verification by the IAEA. Several assumptions are made in this approach.

First, it is assumed that the operator each day would declare the results of cylinder measurements performed and/or reported the previous day by the staff. For example, these would include gross-full weights or gross-empty weights reported for cylinders weighed the previous day, and would include U-235 isotopic analyses and purity (U fraction) analyses as they became available from the laboratory. Of course, each declared value reported by the GCEP operator would have a cylinder number asscciated with it.

Second, it is assumed that the operator would transmit these declarations in an unalterable form on a daily basis to the IAEA. For example, these declarations could be mailed (by express mail) or transmitted by facsimile to the IAEA regional office in Toronto, Ontario, Canada. Of course, the regional 
office staff could confirm and record the arrivai date of each individual declaration.

Third, the operator would retain feed, product, and tails cylinders on site for agreed-upon lengths of time, before they are fed to or shipped from the plant. After expiration of this "residence time", the operator would feed or ship cylinders, regardless of whether the IAEA had verified their contents. Fourth, it is assumed that the IAEA would perform unannounced materia1-balance-verification inspect ons at random time intervals during the year; the approximate average frequency is anticipated to be 12-15 inspections per year for an 1100 tonne SWU/year facility. These inspections would include verification of feed, product, and tails cylinders for which the operator had made declarations of contents.

Based on the above assumptions, the operator would declare (and be committed (o) measurement values as they were performed and became available, but would not know when the IAEA would arrive to verify these declarations. The operator would have no more warning of an unannounced material-balance-verification inspection than he would have of an unannounced cascade-ha11-access inspection.

Fifth, it is assumed that at the time of a random material-balance inspection, the IAEA inspectors would verify weights and U-235 concentrations for cylinders which were declared since the last inspection and which were still resident on site. These verifications could include, but would not be limited to, the following activities. First, the inspectors could receive from the operator (a) a duplicate listing of all the daily declarations made since the last inspection visit and (b) a sumary compilation showing the declared measurement values for each cylinder on site. These data could be provided both in printed form 
and on magnetic tape. The IAEA inspectors could compare the duplicate listing and the summary compilation for consistency with the daily declarations received earlier; this comparison could be made at the inspector's convenience, either onsite or elsewhere. Second, for those cylinders with U-235 concentrations declared since the last inspection, the inspectors could perform nondestructive-assay (NDA) enrichment-attributes measurements for a randomly selected set of cylinders; the number of cylinders selected from each stratum would be calculated from the attributes sample size for that stratum. Third, and also for those cylinders with $\mathrm{U}-235$ concentrations declared since the last inspection, the inspectors randomly could select one or more cylinders for gas-phase sampling. The actual number selected would be calculated from the variables sample size for each stratum. The inspectors also could also request gas-phase samples for any cylinder which failed the enrichment-attributes test. These samples could be analyzed by mass spectrometry at SAL or NWAL. Fourth, for those cylinders with wejghts declared since the last inspection, the inspector could perform weight verifications for a randomly selected set of cylinders; the number of cylinders selected in each stratum would be calculated from the attributes sample size for that stratum. These verifications could be performed with the large-capacity load-cell-based weighing system.

Sixth, it is assumed that the IAEA inspectors would take the compiled and verified daily declarations back to the IAEA headquarters for comparison with the material-balance declarations made 1ater on the Inventory Change Reports (ICRs). Discrepancies between these two sets of declarations would comprise anomalies to be resolved by the operator and the IAEA. If these anomalies could not be resolved or occurred quite frequently, the IAEA might request an increase in inspection frequency or larger sample sizes. 


\section{B. Probability of Detection}

The probability $\left(\mathrm{P}_{D}\right)$ with which the IAEA will detect a falsified cylinder (i.e., cylinder with a defect) depends on the probability ( $p_{i}$ ) that any given cylinder is on site at the time of an IAEA material-balance-verification-inspection, and on the probability $\left(P_{G}\right)$ that the cylinder will be selected for verification if it is on site. It is assumed that the attributes and variables sample sizes will be chosen such that this latter probahility will be $90 \%$. Note that gross defects are detected by the attributes measurements, while smal1 defects (and biases) are detected by the variables measurements. Thus,

$$
P_{D}=P_{G} P_{i}
$$

The following analysis is due to J.B. Sanborn. 5

We firs: consider the case in which the operator needs to falsify the contents of only one cylinder in order to divert a significant quantity of low-enriched uranium (75-kg v-235). This would be the case, for example, with a Mode1 $48 \times\left(10\right.$-ton) cylinder filled with product $\mathrm{UF}_{6}$. The probability that any given cylinder will be on site when the IAEA performs a materia1-balance inspection depends on four factors. These are:

a) the average number of inspections per year;

b) the duration of an inspection;

c) the rate of cylinder processing; and

d) the length of time that a cylinder with declared measurement values resides at the GCEP site.

Let $T_{1}$ be the length of time in days that a cylinder resides at the plant and is available for inspection, after the operator's declaration is made. In addition, let $T_{2}$ be the time interval in days required to fill (or empty) a 
cylinder in a particular stratum, so that the rate of cylinder production or flow is $1 / T 2$. The parameter $T_{2}$ will have different values for fead, product, and tails streams. Let $T_{3}$ be the duration (in days) of a single inspection.

Since the schedules for cylinder filling, sampling, and weighing are predictable, the inspector could time his visits so that he need only see cylinciers that were not previously verified by him. Moreover, if he also is to have the chance to see all the cylinders in the given stratum, then the time interval in days, $T_{i}$, between the beginnings of two inspections is given by

$$
T_{i}=T_{2} \operatorname{Int}\left(\left(T_{1}+T_{3}\right) / T_{2}+1\right)
$$

where "Int" indicates the integer part of that which follows (e.g., Int $(3.6)=$ 3). The number of visits per year $\left(N_{i}\right)$ necessary in order to verify all cyinders is then given for each stratum by:

$$
N_{i}=\frac{365}{T_{i}}
$$

However, if the number of inspections per year is 1 imited to $N$, then it may be necessary to conduct each above inspection with some probability less than one. For each stratum, let $P_{i}$ be the probability that any given cylinder will be on site at the time of a random inspection.

Then

$$
\begin{gathered}
P_{i}=\frac{N}{N_{i}}=\frac{N T_{i}}{365} \\
P_{i}=\frac{N T_{2}}{365} \operatorname{Int}\left(\left(T_{1}+T_{3}\right) / T_{2}+1\right)
\end{gathered}
$$

where $N$ is the average number of inspections per year. 
Finally, the probability $\left(P_{D}\right)$ of detecting one defected cylinder (either by attributes or variables measurements) is given by:

$$
P_{D}=0.90 \frac{N T_{2}}{365} \operatorname{Int}\left(\left(T_{1}+T_{3}\right) / T_{2}+1\right)
$$

when only one cylinder needs to be falsified in order to divert a significant quantity.

We now consider the case in which the operator must falsify the contents of more than one cylinder in order to divert a significant quantity of uranium. Let $n$ be the number of cylinders that must be so falsified. It can be shown that the diverter's best strategy is to defect (falsify) these $n$ cylinders sequentially, rather than distributing the $n$ individual falsifications throughout the year. It also can be shown that the probability of detection in this case becomes

$$
P_{D}=0.9 \frac{N T_{2}}{365} \text { Int }\left(\left(T_{1}+(n-1) T_{2}+T_{3}\right) / T_{2}+1\right)
$$

These relationships are summarized in Table II, while the parameters used in the present calculation are summarized in Table III.

C. Results

1. Product Cylinders

We consider first the case of product cylinders, for which the opsrator only needs to falsify the enrichment or weight of one cylinder in order to divert an LEU significant quantity. For product cylinders produced by an 1100 tonne SWU/yr GCEP, $\mathrm{T}_{2}=7.5$ days. Figure 1 gives the detection probability 
Table II

Detection Probabilities for the Intermittent Inspection Approach

$$
P_{D}=0.9 \frac{N T_{2}}{365} \operatorname{Int}\left(\left(T_{1}+(n-I) T_{2}+T_{3}\right) / T_{2}+1\right)
$$

where for each stratum:

$P_{D}=$ Probability that a cylinder with a defect will be detected

$N=$ Average number of inspections per year

$\mathrm{n}=$ Number of cylinders that must be defected to obtain a goal quantity

$T_{1}=$ Time (days) that a cylinder resides at GCEP after operator's declaration is made

$T_{2}=$ Time (days) required to fill or empty a cylinder

$T_{3}=$ Duration (days) of a single inspection

Int $=$ Integer part of expression that follows 
Table III

Parameters for Calculation of Detection Probability $P_{D}$

(Separative Capacity of 1100 tonne SWU/year)

Time (days) that a cylinder resides at GCEP after operator's declaration is made

Time (days) required to fill or empty a cylinder

Feed

Product

Tails

Duration (days) of a single inspection

Number of cylinders that must be

falsified to obtain $75 \mathrm{~kg} \mathrm{U}-235$

Feed

Product

Tails

Average number of inspections per year
$\mathbf{T}_{1}$

Variable

$T_{2}$

1.5

7.5

2.2

$\mathbf{T}_{3}$

2-5

n

2

1

N

$12-15$ 
$P_{D}$ as a function of $T_{1}$ when there are $N=12$ inspections per year; the several lines correspond to several values of the inspection duration $\left(T_{3}=2,3\right.$, and 5 days). Similarly, Figure 2 gives the detection probability $P_{D}$ as a function of $\mathrm{T}_{1}$ For $\mathrm{N}=15$ inspections per year. In the latter case, moderate detection probabilities $\left(P_{D}=0.55\right)$ are achieved for relatively small values of $T_{1}\left(T_{1}=\right.$ 3-6 days), but large detection probabilities $\left(P_{D}=0.8-0.9\right)$ are achieved only for larger values of $T_{1}\left(T_{1}\right.$ greater than 10 days). As an aid to the reader, the case $\mathbf{N}=20$ is included as Figure 3 .

\section{Feed Cylinders}

We next consider the case of feed cylinders, for which the operator only needs to falsify the encichment or weight of two cylinders in order to divert an LEU significant quantity. For feed cylinders used at an 1100 tonne SWU/year GCEP, $\mathrm{T}_{2}=1.5$ days. Figure 4 gives the detection probability $\mathrm{P}_{\mathrm{D}}$ as a function of $T_{1}$ when there are $N=12$ inspections per year; the several 1 ines correspond to several values of the inspection duration $\left(T_{3}=2,3\right.$, and 5 days). Similarly, Figure 5 gives the detection probability $P_{D}$ as a function of $T_{1}$ for $N=15$ inspections per year. It is helpful in understanding these figures to note that the graphs for the various $T_{3}$ do not cross one another. For 15 inspection per year, large detection probabilities $\left(P_{D}=0.8-0.9\right)$ are achieved for $T_{1}$ values of 15 days or greater. However, such $T_{1}$ values should not be difficult to achieve at GCEP, since it is planned to have a feed-cylinder inventory corresponding to 75 days of feed, and to handle this stockpile on a first-in, first-out basis. The IAEA should have anple opportunity to verify feed cylinders during this 75 -day period. As an aid to the reader, the case $N=20$ is included as Figure 6. 


\section{Tails cylinders}

Finally, we consider the tails cylinders. For an 1100 tonne SWU/year GCEP, $T_{2}=2.2$ days. However, each tails cylinder contains only $22 \mathrm{~kg}$ U-235, so that the operator must falsify the contents of four cylinders in order to divert a significant quantity $(75 \mathrm{~kg} \mathrm{~V}-235)$. It can be shown that the operator's best strategy in falsifying these tails cylinders is to falsify four cylinders in sequence (rather than distributing four single-cylinder falsifications over the yearj, and our detection probabilities are calculated for this optimal strategy. Figure 7 gives the detection probability $P_{n}$ as a function of $T_{1}$ when there are $N=12$ inspections per year; as above, the severa1 1 ines correspond to several values of the inspection duration $\left(T_{3}=2,3\right.$, and 5 days), and the lines do not cross one another. Similarly, Figure 8 gives the detertion probability $P_{D}$ as a function of $T_{1}$ for $N=15$ inspections per year. For 15 inspections per year, large detection probabilities $\left(P_{D}=0.8-0.9\right)$ are achieved for $T_{1}$ values of 8 days or greater. The case $N=20$ is included as Figure 9 .

\section{Summary}

The above calculations indicate that high detection probabilities would require that product and tails cylinders be held at the GCEP site several days longer than would be required strictly from plant operational considerations. However, an evaluation of the overall effectiveness of safeguards should take account of the deterrence contribution from the unannounced random character of the inspection activities, which may make somewhat lower detection probabilities acceptable. 


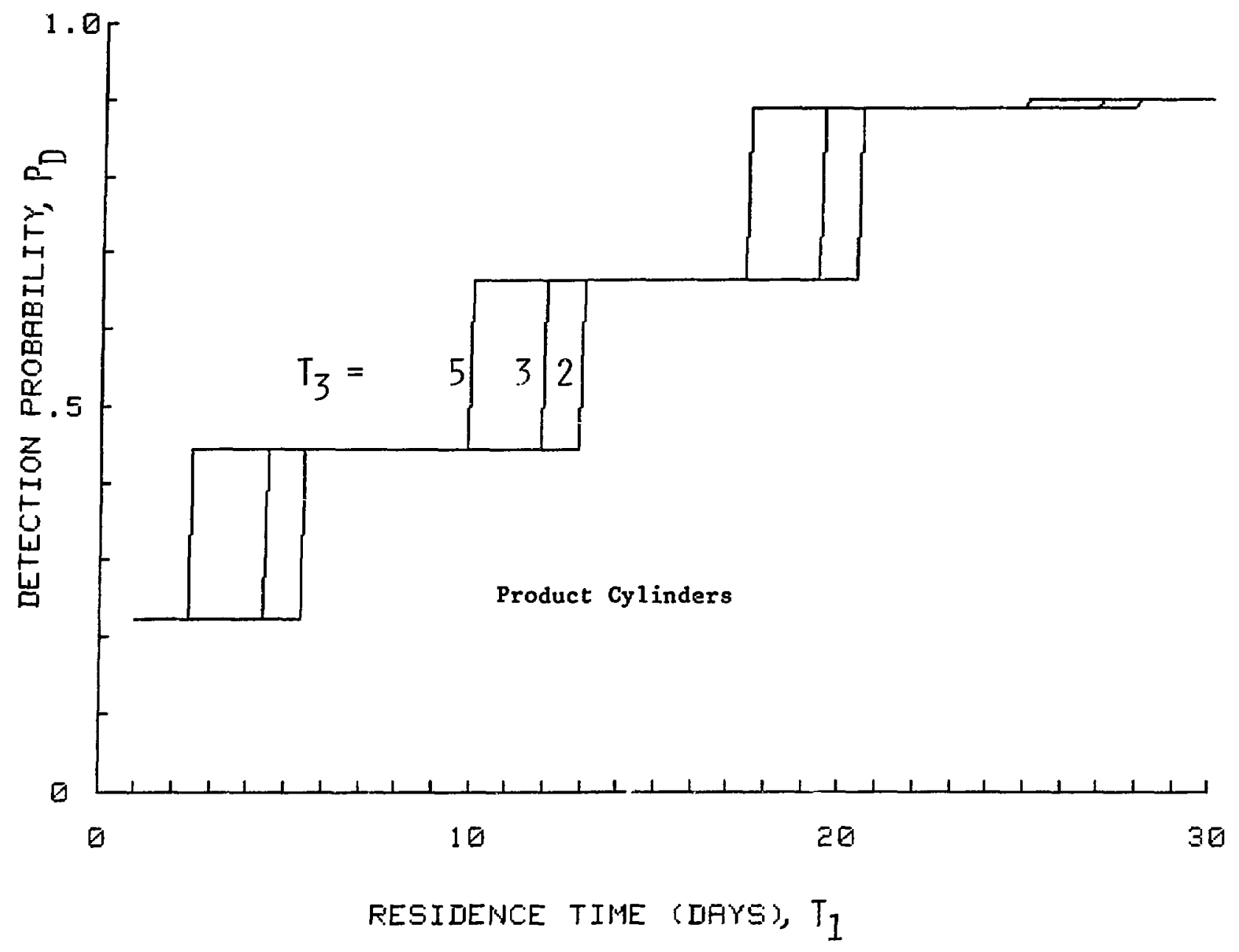

Figure 1

Detection Probability $\left(P_{D}\right)$ as a Function of Residence

Time $\left(T_{1}\right)$ for $N=12$ Inspections per Year 


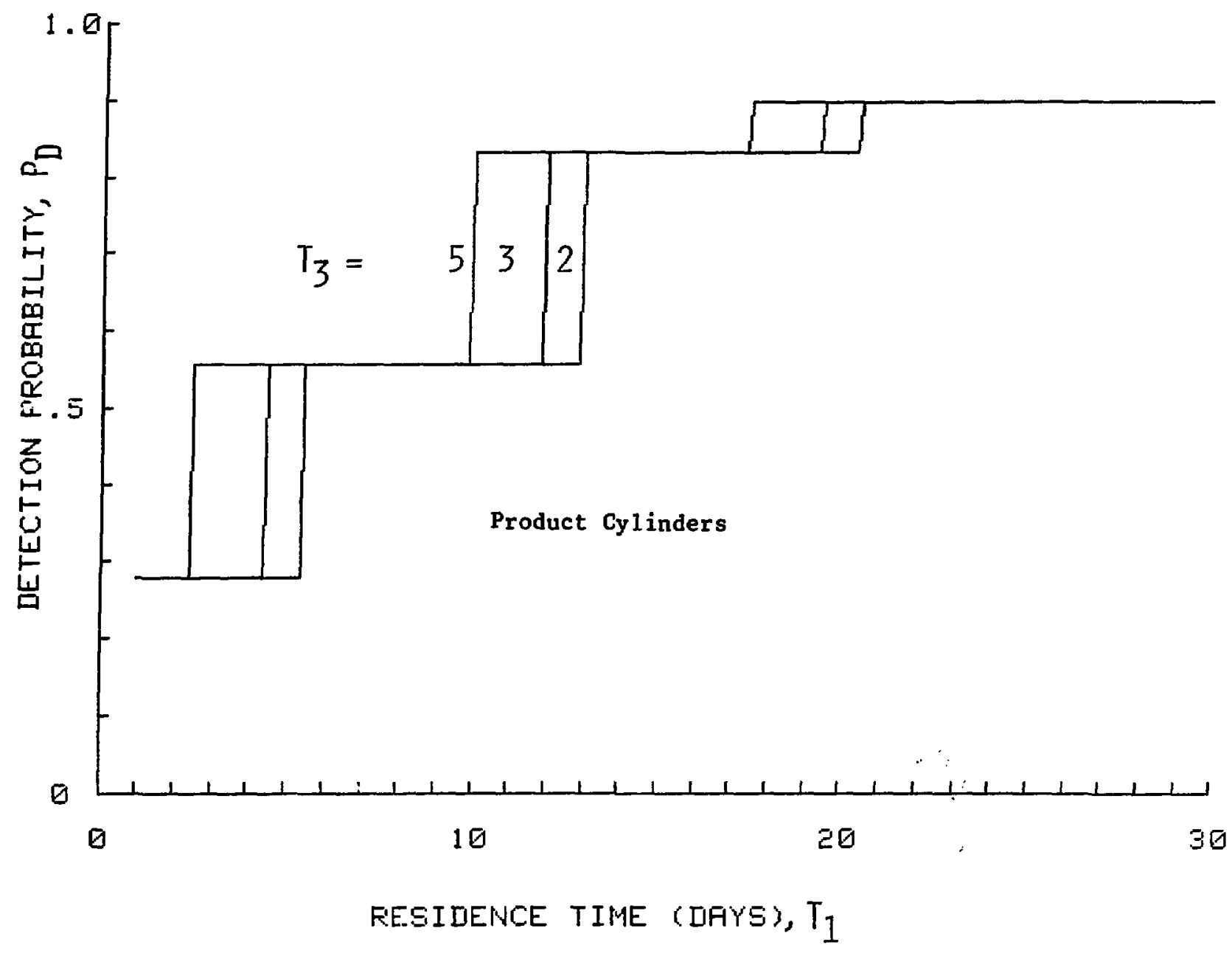

Figure 2

Detection Probability $\left(P_{D}\right)$ as a Function of Residence

Time $\left(T_{1}\right)$ fo: $N=15$ Inspections per Year 


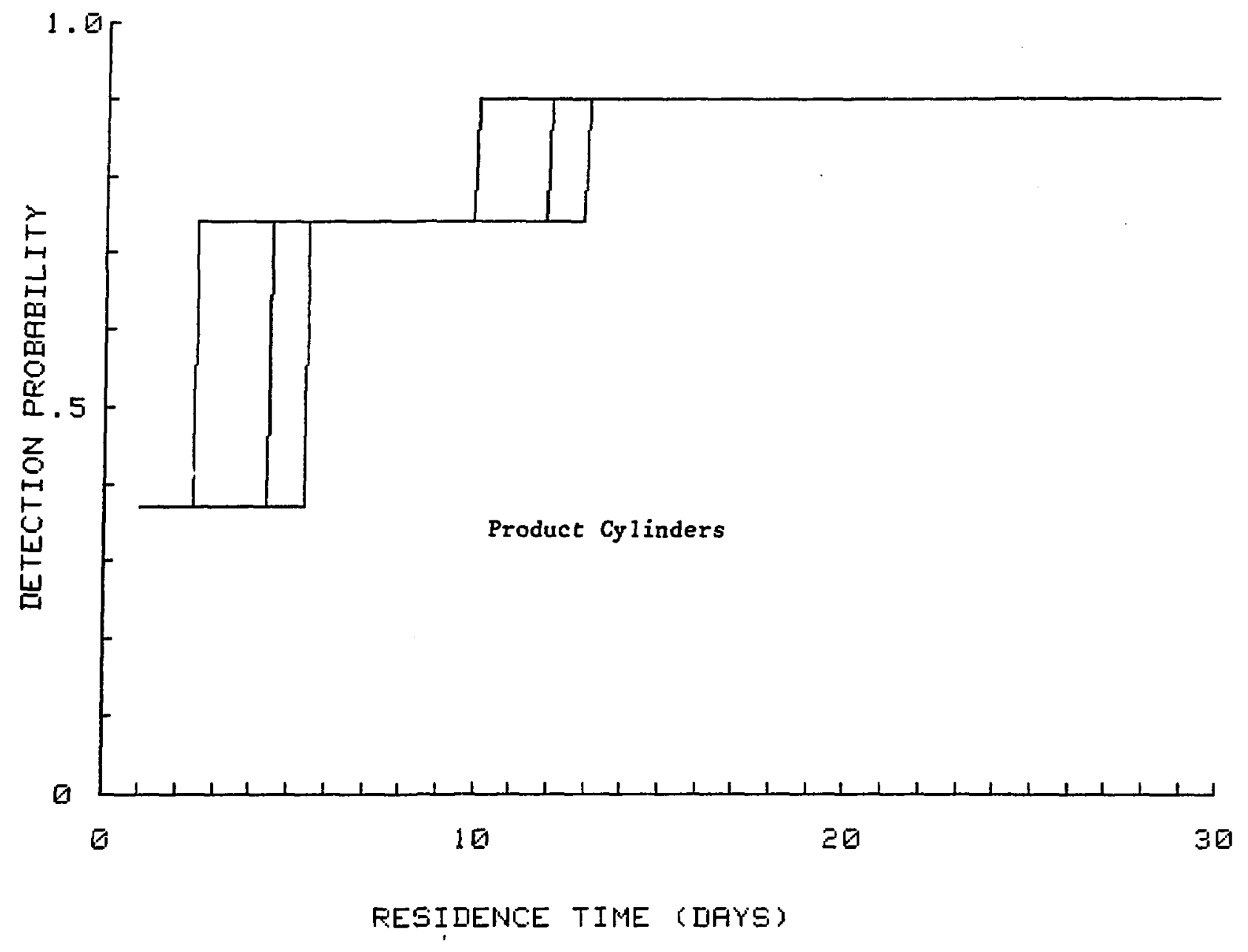

Figure 3

Detection Probability $\left(P_{D}\right)$ as a Function of Residence

Time $\left(T_{1}\right)$ for $N=20$ Inspections per Year 


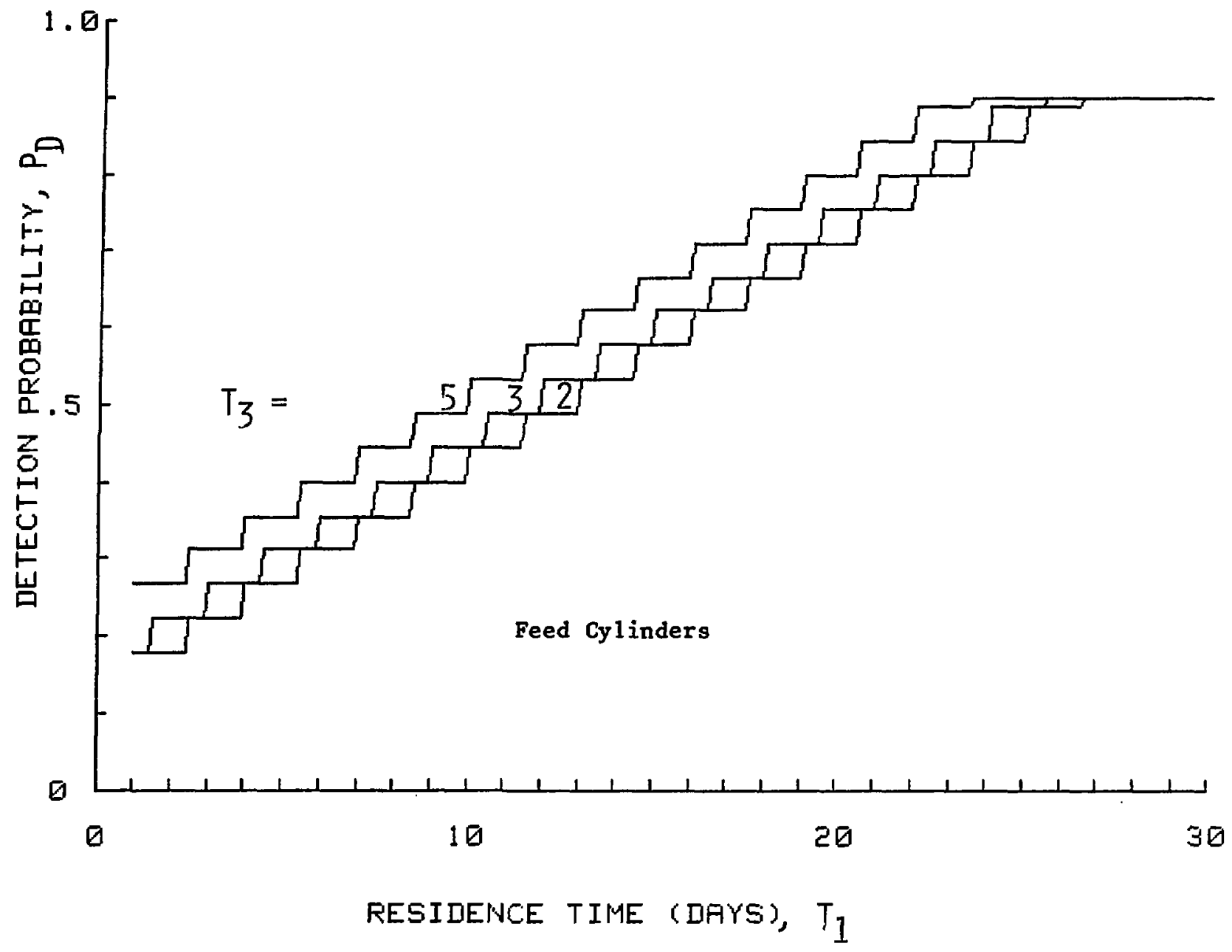

Figure 4

Detection Probability $\left(P_{D}\right)$ as a Function of Residence

Time $\left(T_{1}\right)$ for $N=12$ Inspections per Year 


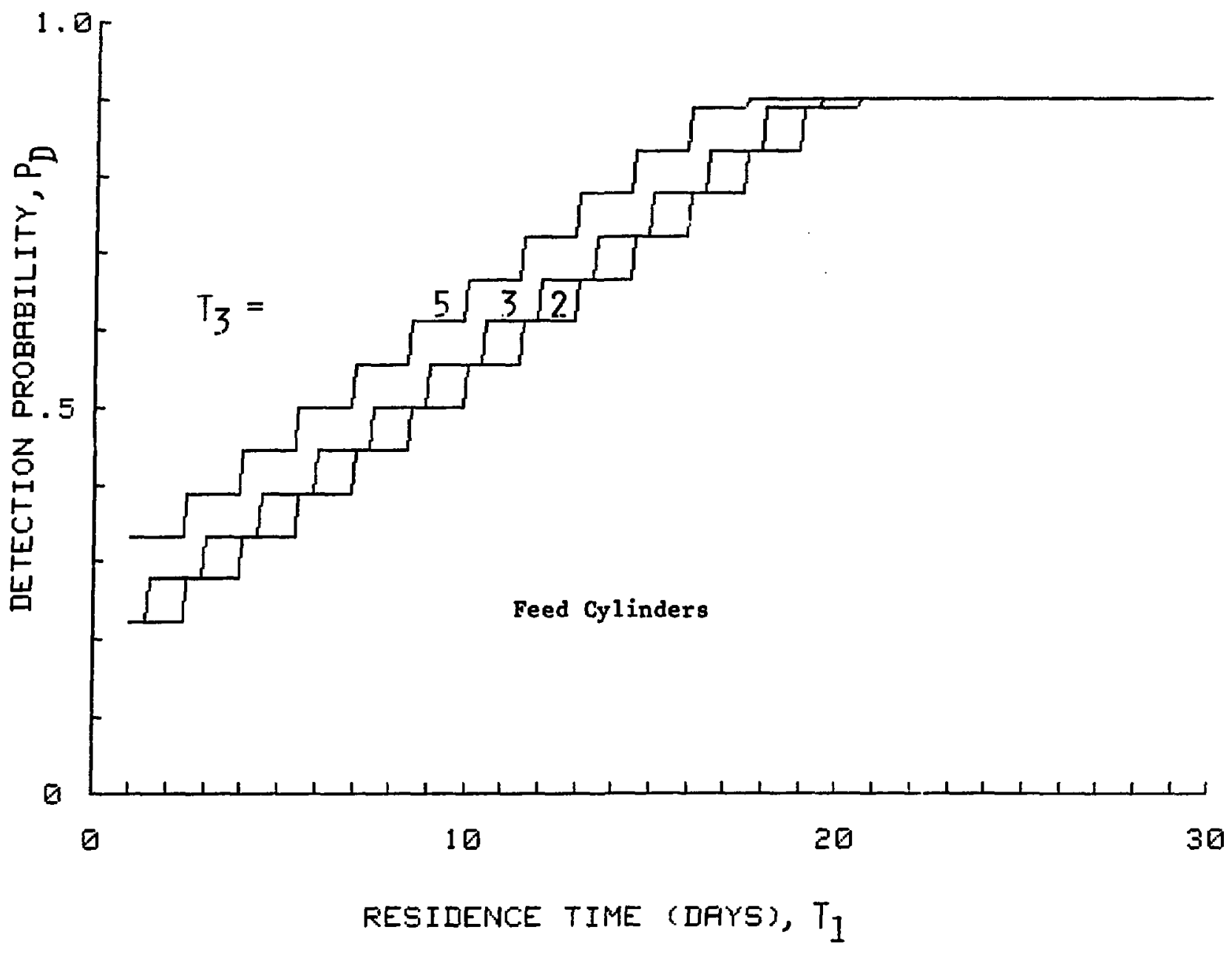

Figure 5

Detection Probability $\left(P_{D}\right)$ as a Function of Residence

Time $\left(T_{1}\right)$ for $N=15$ Inspections per Year 


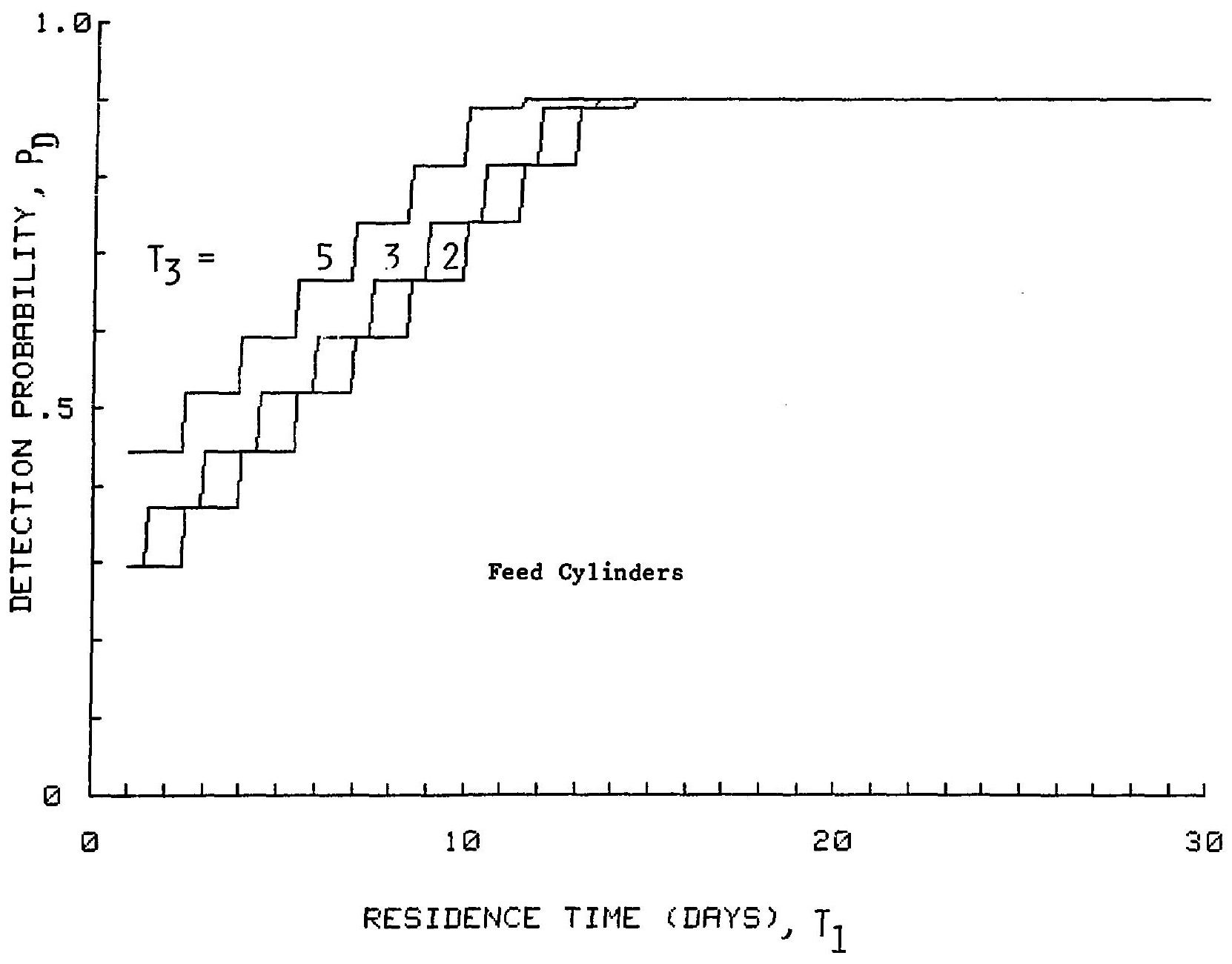

Figure 6

Detection Probability $\left(P_{D}\right)$ as a Function of Residence

Time $\left(T_{1}\right)$ for $N=20$ Inspections per Year 


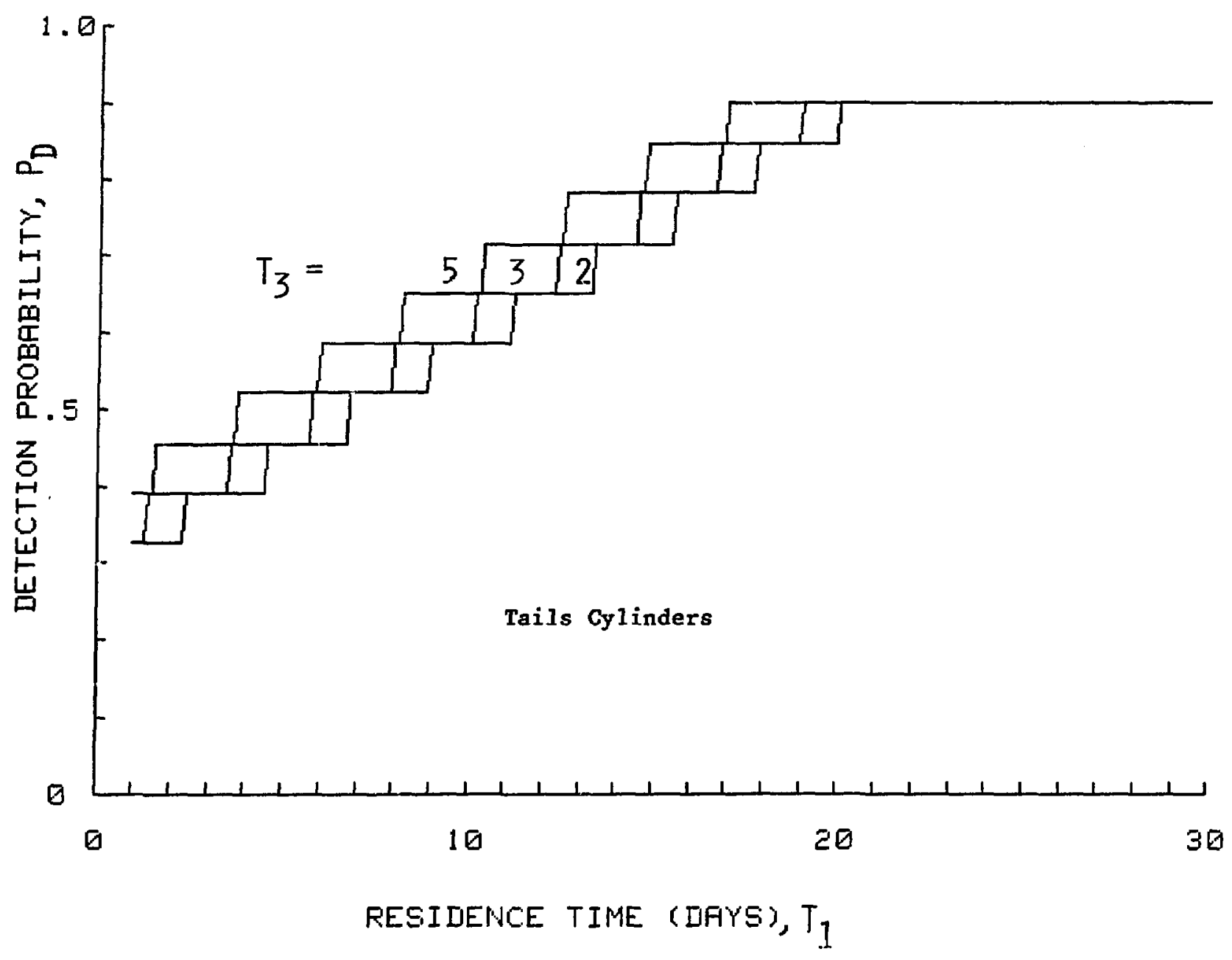

Figure 7

Detection Probability $\left(P_{D}\right)$ as a Function of Residence

Time $\left(T_{1}\right)$ for $N=12$ Inspections per Year 


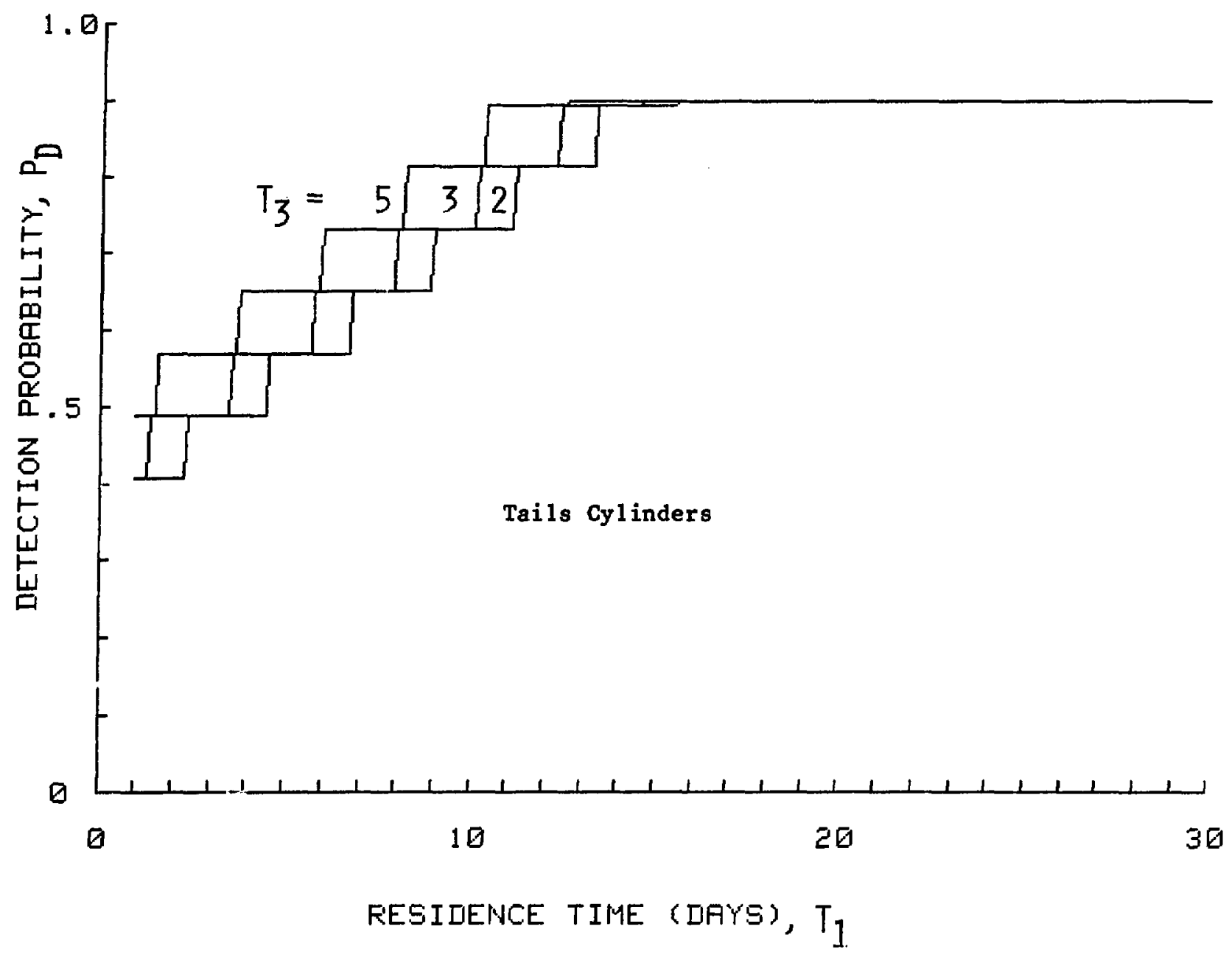

Figure 8

Detection Probability $\left(P_{D}\right)$ as a Function of Residence

Time $\left(T_{1}\right)$ for $N=15$ Inspections per Year 


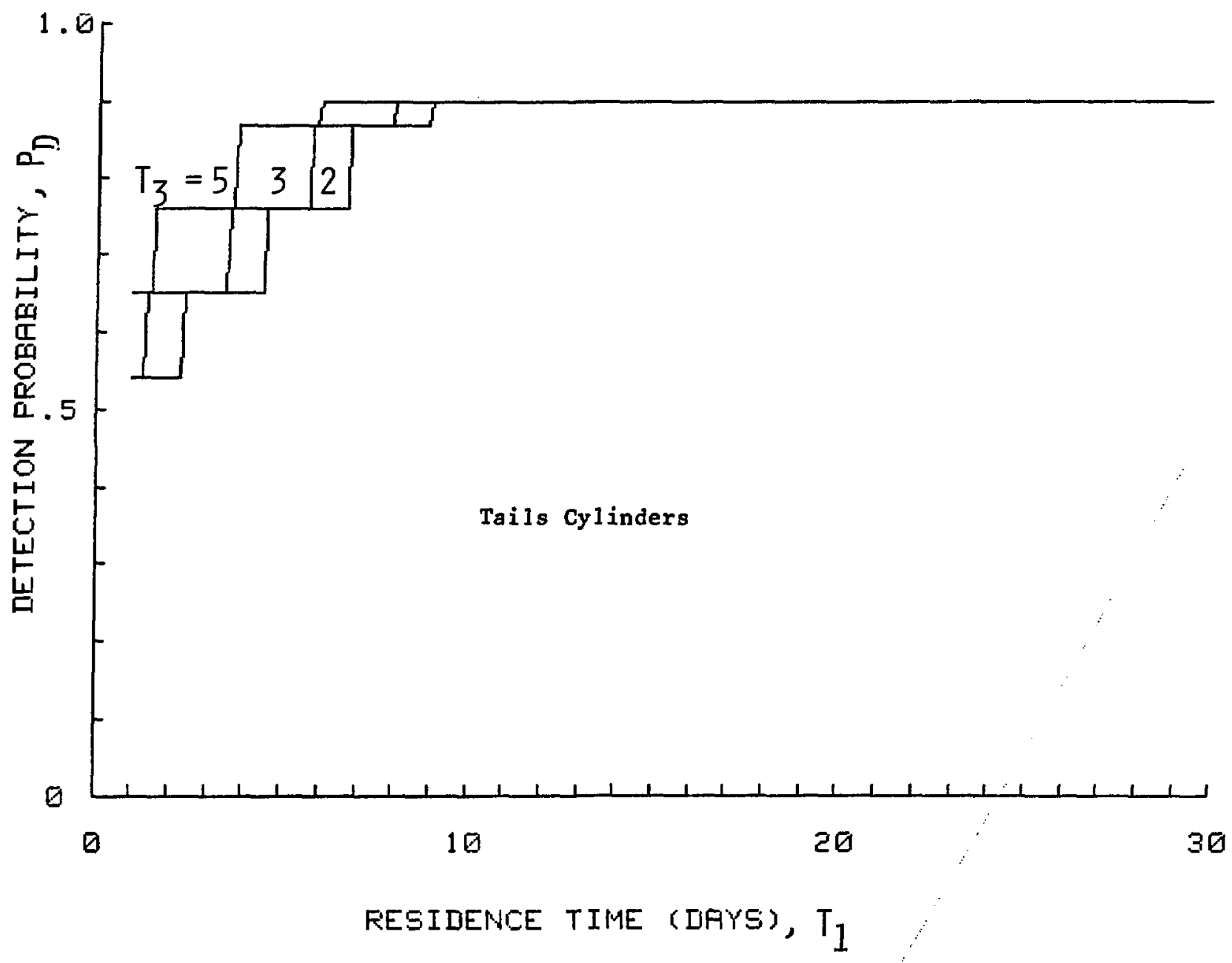

Figure 9

Detection Probability $\left(P_{D}\right)$ as a Function of Residence

Time $\left(T_{1}\right)$ for $N=20$ Inspections per Year 


\section{References}

1. "Safeguards Approach for Gas Centrifuge Type Errichment Plants", authored by the Hexapartite Safeguards Project, edited by J.H. Menzel, Journal of the Institute of Nuclear Materials Management, Vol. XII, No. 4, Winter 1983, pp. 30-37.

2. International Atomic Energy Agency, IAEA Safeguards Technical Manual, Part F, Statistical Concepts and Techniques, Volume 3, IAEA-TECDOC-261, IAEA, Vienna (1982).

3. D.M. Gordon, J.B. Sanborn, J.M. Younkin, and V.J. DeVito, "An Approach tc IAEA Materia1-Balance Verification at the Portsmouth Gas Centrifuge Enrichment Plant", Proceedings of the Fifth Annual Symposium on Safeguards and Nuclear Material Management, Versailles, France, April 19-21, 1983, ESARDA 16, PP. 39-43.

4. Private communication, L.M. Brenner (U.S. Department of Energy) to D.M. Gordon, January 1983.

5. Private communication, J.B. Sanborn to D.M. Gordon, February 25, 1983.

$\mathrm{DG} / \mathrm{nd} / 14$ 